\title{
Un tejido único Moche III del sitio Castillo de Santa: una escena de cosecha de yuca
}

Un tissu unique Moche III du site El Castillo de Santa : une scène de récolte de yucca

A unique Moche III textile from El Castillo site of Santa: a harvest scene of yucca

\section{Claude Chapdelaine y Víctor Pimentel}

\section{(2) OpenEdition}

Journals

Edición electrónica

URL: http://journals.openedition.org/bifea/6327

DOI: $10.4000 /$ bifea.6327

ISSN: 2076-5827

Editor

Institut Français d'Études Andines

Edición impresa

Fecha de publicación: 1 abril 2003

Paginación: 23-50

ISSN: 0303-7495

\section{Referencia electrónica}

Claude Chapdelaine y Víctor Pimentel, « Un tejido único Moche III del sitio Castillo de Santa: una escena de cosecha de yuca », Bulletin de l'Institut français d'études andines [En línea], 32 (1) | 2003, Publicado el 08 abril 2003, consultado el 08 diciembre 2020. URL : http://journals.openedition.org/ bifea/6327 ; DOI : https://doi.org/10.4000/bifea.6327

\section{(@) $\odot \Theta$}

Les contenus du Bulletin de l'Institut français d'études andines sont mis à disposition selon les termes de la licence Creative Commons Attribution - Pas d'Utilisation Commerciale - Pas de Modification 4.0 International. 


\title{
UN TEJIDO ÚNICO MOCHE III DEL SITIO CASTILLO DE SANTA: UNA ESCENA DE COSECHA DE YUCA
}

\author{
Claude CHAPDELAINE, Víctor PIMENTEL*
}

\section{Resumen}

Durante el mes de julio de la temporada 2002 en la Terraza Este del sitio El Castillo, valle de Santa, encontramos la tumba de un niño envuelto con varios tejidos. Uno de ellos es único e ilustra una escena de cosecha de una planta identificada como la mandioca o yuca. El contexto arqueológico indica que se trata de un entierro fechado para la fase Moche III, basado en el contenido de los rellenos entre los pisos ubicados arriba y debajo de la tumba. Se describe el tejido en su contexto y se discute sobre su naturaleza y las implicaciones en la economía Moche.

Palabras claves: Arqueología, cultura Moche, patrón funerario, tejido decorado, economía agraria, yuca.

\section{UN TISSU UNIQUE MOCHE III DU SITE EL CASTILLO DE SANTA : UNE SCÈNE DE RÉCOLTE DE YUCCA}

\section{Résumé}

Les fouilles archéologiques effectuées sur la terrasse Est du site El Castillo en juillet 2002, dans la vallée de Santa, ont conduit à la découverte de la tombe d'un enfant enroulé dans plusieurs textiles. L'un d'eux est unique et illustre une scène de récolte d'une plante identifiée comme étant le manioc ou yucca. Le contexte archéologique indique un enterrement datant de la phase Moche III si on considère le contenu des remplissages entre les planchers sous et audessus de la tombe. Le textile est décrit dans son contexte et une discussion sur sa nature et les implications de son message sur l'économie Moche est amorcée.

Mots clés : Archéologie, culture Moche, patron funéraire, textile décoré, économie agraire, yucca.

\section{A UNIQUE MOCHE III TEXTILE FROM EL CASTILLO SITE OF SANTA: A HARVEST SCENE OF YUCCA}

\section{Abstract}

Archaeological fieldwork carried out in July 2002 on Terrace East at El Castillo site, Santa Valley, resulted in the discovery of a child burial wrapped in many textiles. One of them is unique.

* Département d'anthropologie, Université de Montréal, C.P. 6128, succursale Centre-Ville, Montréal, QC, H3C 3J7, Canada. E-mails: chapdelc@anthro.umontreal.ca; pimentev@magellan. umontreal.ca 
It represents a harvest scene of the plant identified as the manioc or yucca. The archaeological context indicates a Moche Phase III date for the burial based of the content of the fill between plastered clay floors from over and under the tomb. Description of the textile's context is followed by a discussion of its nature and possible implications on Moche economy.

Key words: Archaeology, Moche Culture, Funerary Pattern, Decorated Textile, Agrarian economy, Yucca.

\section{INTRODUCCIÓN}

De todos los sitios Moche conocidos en la parte baja del valle de Santa, el sitio El Castillo es el que ha llamado más nuestra atención durante los tres primeros años de nuestro proyecto de largo plazo sobre la presencia Moche en el valle de Santa (1). Hemos igualmente realizado excavaciones arqueológicas en los sitios Guadalupito, Huaca China (Chapdelaine et al., s.f.), Hacienda San José, Guad-88 y Guad-121 (Fig. 1).

El sitio El Castillo ocupa todo el contorno y la cima de una colina que se eleva al menos 80 metros sobre el nivel de la planicie que la rodea (Fig. 2). El sitio ha sido considerado como un centro regional (Wilson, 1988) y la presencia Moche se remonta por lo menos a la fase III (Donnan, 1973). Hemos dividido el sitio de la siguiente manera: 1) Terraza Norte, que abarca toda la parte al norte de la superficie nivelada en la cima y que termina con un gran muro de contención bien identificado por Wilson (1988: 210); 2) Terraza Este, constituida por varios niveles que pueden ser agrupados en una sección alta y una sección baja; 3) Sector Alto, que corresponde a toda la superficie acondicionada de la cima; 4) Terraza Sur, que es una franja estrecha, de aproximadamente 20 metros de ancho, que bordea la cima y cuya pendiente bastante abrupta se prolonga hasta la base del cerro; 5) Zona Oeste, todavía mal definida, que en buena parte corresponde a la sección baja de la cima acondicionada y a la prolongación de la Terraza Norte hacia el oeste (Fig. 2).

La colina fue primero acondicionada por grupos de la cultura Gallinazo, después por los Moche y luego por grupos Tanguche. Si la cima y las terrazas Este y Oeste fueron ocupadas principalmente por los Gallinazo, la terraza Norte fue ciertamente el centro principal de ocupación de los Moche, aun cuando también se encuentran sus huellas en diferentes niveles de la Terraza Este. En cuanto a los grupos Tanguche, sus vestigios son más numerosos en la Terraza Este, pero también se han recuperado vasijas típicas de este período en la Terraza Norte.

El sitio El Castillo, de naturaleza monumental, con una huaca en la cima de origen Gallinazo, y una segunda en el flanco norte y de origen Moche, constituye un verdadero laboratorio para estudiar la sucesión de las ocupaciones pero también para tratar de comprender las relaciones entre los grupos que allí se sucedieron. Es

(1) Los datos de este artículo provienen de un proyecto de largo plazo sobre la presencia Moche en el valle de Santa. El Proyecto Santa de la Universidad de Montreal (PSUM) está subvencionado por el Consejo de Investigaciones en Ciencias Humanas del Canadá (CRSHC) por un período de tres años (2000-2003). 


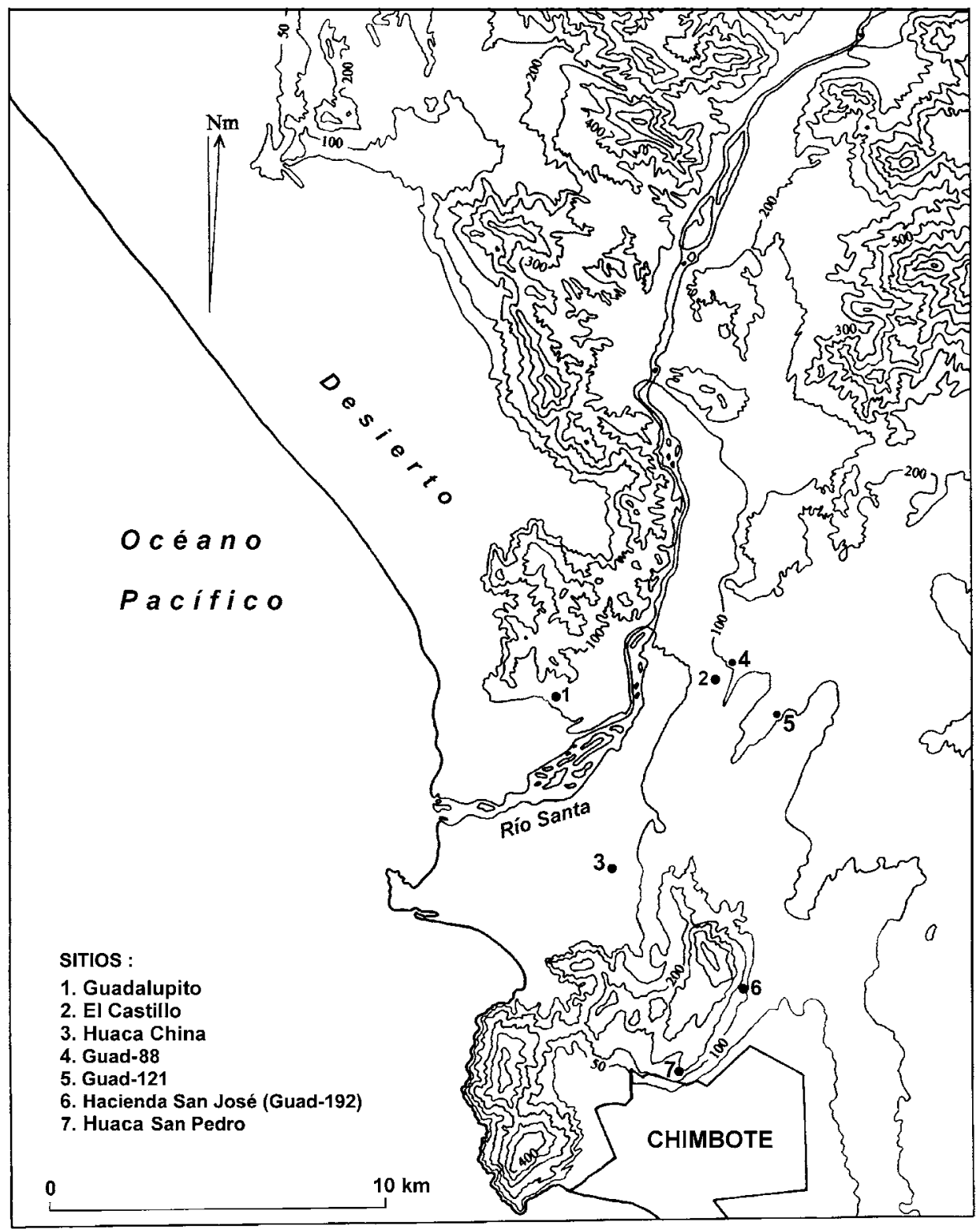

Fig. 1 - Sitios arqueológicos mencionados. 


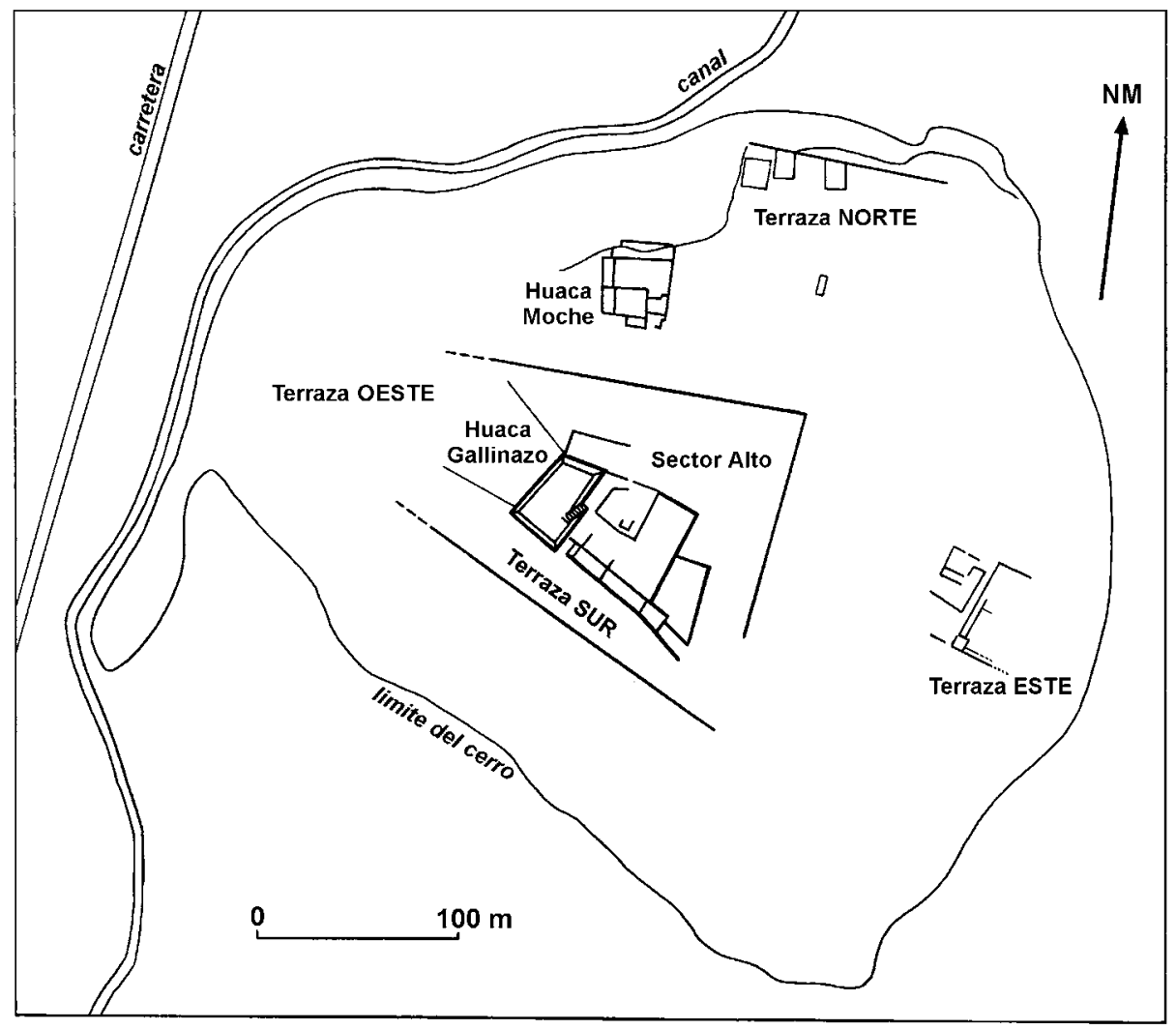

Fig. 2 - Plano del sitio El Castillo.

precisamente en esta perspectiva que se inscribían nuestros trabajos en la Terraza Este durante la temporada 2002. Excavamos en la sección baja con la finalidad de entender la presencia Moche y de buscar evidencias sobre la relación entre las ocupaciones Moche y Gallinazo.

En este artículo, deseamos primero presentar el contexto del descubrimiento de un tejido excepcional al igual que la tumba, el individuo inhumado en ella, su ajuar funerario y las tumbas relacionadas. Presentamos a continuación una discusión sobre el tejido mismo y las implicaciones de su mensaje iconográfico para el entendimiento de la economía agraria Moche y su pertinencia en el contexto de un estado expansionista.

\section{TERRAZA ESTE BAJA DE EL CASTILLO}

Para comprender bien la evolución de las excavaciones en la Terraza Este es útil recordar brevemente los resultados obtenidos antes de las excavaciones del 2002. Así, el hecho sobresaliente de la temporada 2000 en la parte baja de la Terraza Este fue el descubrimiento de una ocupación de la cultura Tanguche y la ausencia de una ocupación de la cultura Moche (Chapdelaine \& Pimentel, 2001). En vista de este 
resultado, consideramos la posibilidad que los Moche no ocuparan esta vertiente de la colina y que los nuevos dirigentes decidieran aprovechar este lugar para instalar en él un centro de producción y de control. Esta ocupación Tanguche no había sido puesta en relieve previamente (Wilson, 1988: 230, 265), aunque Donnan mencionaba ya la presencia de cerámica del Horizonte Medio en varios sectores de este sitio (Donnan, 1973: 40-41).

El año 2001 efectuamos dos pequeñas excavaciones en un área adyacente a la excavada el 2000, pero en un nivel más bajo (Fig. 3), con la finalidad de verificar la ausencia de una ocupación Moche, así como para obtener más datos sobre la presencia Tanguche (Chapdelaine \& Pimentel, 2002). A pesar del poco tiempo invertido en la Terraza Este en el 2001, los resultados fueron sorprendentes. Las dos pequeñas áreas de excavación se encuentran al sureste de la gran habitación Tanguche y pensamos que esta área había sido utilizada como un espacio abierto, posiblemente una plaza con acceso a la terraza superior ubicado en la esquina formada por el paramento que se extiende hacia el norte y el muro que cierra la plaza por el lado sur (Fig. 3). Dos conclusiones se desprenden de las excavaciones del año 2001. La primera es la rareza de restos asociados a la cultura Tanguche en la capa superficial a pesar de su proximidad a la estructura Tanguche excavada el 2000. La segunda es la identificación de una fuerte presencia Moche con la existencia, bajo la sucesión de capas Moche, de vestigios cerámicos atribuibles a la cultura Gallinazo. No habíamos previsto encontrar elementos de una presencia Gallinazo a menos de un metro de profundidad debajo del primer piso. En efecto, hallamos fragmentos de bordes de cerámica doméstica típica de la cultura Gallinazo en las capas inferiores de la secuencia de capas culturales.

Para entender las ocupaciones de la parte baja de la Terraza Este, el lector debe saber que esta se puede dividir en tres niveles de terrazas: la terraza alta delimitada por el primer muro de contención construido con piedras enormes; la terraza intermedia, con la ocupación Tanguche, donde trabajamos el 2000; la terraza baja, donde se encuentra la plaza excavada el 2001 y donde se concentraron la mayoría de nuestros esfuerzos el 2002 (Fig. 3).

En la terraza baja registramos dos fases constructivas atribuidas a los Moche y descubrimos tres tumbas en un contexto asociado al final de la primera fase, dentro de la capa de relleno sobre la cual se construyó la última fase de construcción, la misma que cubrió las tumbas (Fig. 3).

La última fase constructiva corresponde a una gran plaza. Excavamos hasta el primer piso y confirmamos la presencia de la referida plaza. Se trata de un área abierta que limita por el sur y el oeste con muros. El límite este corresponde al camino moderno al lado del canal de irrigación que delimita la parte baja de la Terraza Este. No tenemos el límite norte, pero se puede evaluar su existencia frente al límite norte del ambiente \#1 del conjunto \#1 de la cultura Tanguche (Fig. 3). Falta la verificación, aunque el desnivel de la superficie parece efectivamente cubrir un muro. Si nuestras estimaciones son correctas, la plaza tiene más de 40 metros de norte a sur por aproximadamente 20 metros de este a oeste. La plaza abarcaba una superficie importante, de 800 metros cuadrados, que se relacionaba con una estructura de 3 metros de altura y con muros pintados, que dominaba la plaza desde la esquina suroeste.

En la terraza baja hemos verificado la presencia de una gran plaza ceremonial, en la cual no había evidencias de una fuerte ocupación Tanguche. Recolectamos algunos 


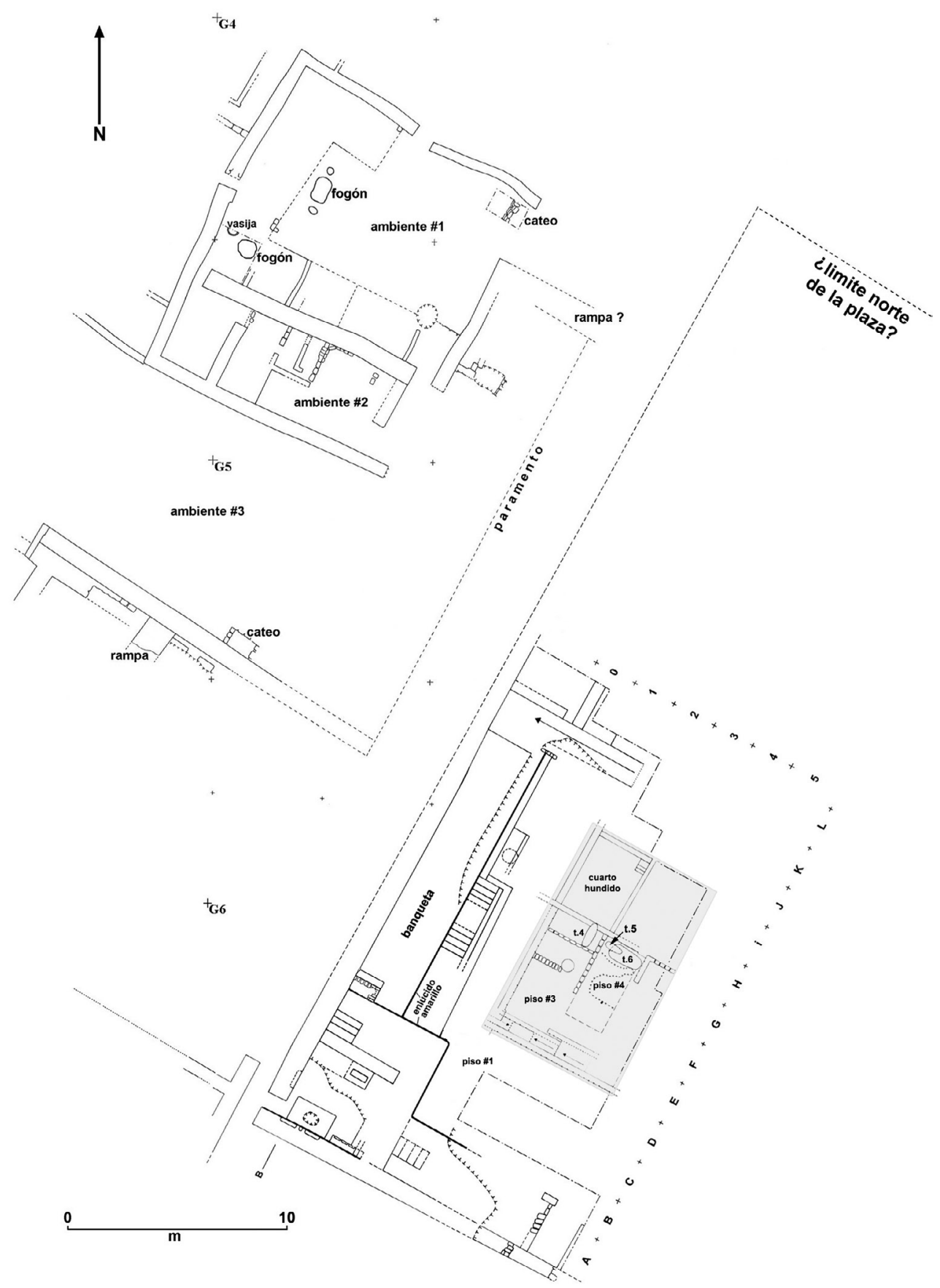

Fig. 3 - Plano de la Terraza Este, sección baja, El Castillo. La zona en gris corresponde a la arquitectura asociada con los pisos \#3 y \#4. 
ceramios típicos de esta cultura e identificamos una rampa frontal, ubicada al noroeste de nuestra área de trabajo, que permitía acceder a la banqueta superior (Fig. 3).

En el plano del área excavada se puede observar un sistema de banquetas con escaleras (Fig. 3). Desde el nivel del piso de la plaza, una escalera con tramos opuestos permite subir a una banqueta alargada. De esta banqueta, una segunda escalera da acceso a la banqueta superior, donde se encuentran los restos de una estructura parecida a la base de un trono. Esta base mide 1,15 por 1,90 m y su elevación es de apenas 20 $\mathrm{cm}$. Un pequeño pozo en el centro podía servir para apoyar una vasija, un asiento o ser un hoyo de huaquero. El muro ubicado detrás del trono presenta decoración mural muy erosionada y hemos definido claramente una figura que podría representar un ave (Chapdelaine et al., 2003: figura 17). También se puede acceder a la parte superior de esta estructura por medio de una escalera adosada al muro de contención del lado este. Esta construcción asociada a una plaza debió tener un rol preciso en este sector del sitio El Castillo. Está ubicada frente a los campos de cultivos y está retirada del sector principal del poder Moche localizado en la Terraza Norte donde se encuentra igualmente la Huaca con murales. Esta banqueta superior o plataforma ubicada en la esquina suroeste de la gran plaza tuvo seguramente una importancia política como también religiosa. El análisis de la cerámica asociada a esta construcción permite establecer que se trata de una ocupación de la fase Moche III.

La exposición del segundo piso confirmó la persistencia de la Plaza. Después de alcanzar el segundo piso, redujimos el área de trabajo a 10 metros en dirección este-oeste y 20 metros en dirección norte-sur. Debajo del piso \#2, las excavaciones más profundas permitieron la definición de una segunda fase constructiva con algunas remodelaciones. La arquitectura asociada con los pisos \#3 y \#4, el tipo de adobes, así como la gran cantidad de cerámica típica de la fase Moche III confirman su filiación mochica.

Sobre el piso \#3 se encontró muros, rampas y tres sepulturas. Estos elementos están asociados con los pisos \#3 y \#4 (se encuentran dentro de la zona gris de la Fig. 3 para distinguirlos de la arquitectura asociada con los pisos \#1 y \#2). La organización de los muros es difícil de establecer y no hay ambientes bien definidos, excepto un cuarto hundido que mide 3,50 m de largo por 2,60 de ancho y 1,10 $\mathrm{m}$ de profundidad. Este ambiente está asociado con el piso \#3, el mismo que forma media caña con el paramento exterior de los muros sur y este; sin embargo el piso al interior de este recinto se encuentra al mismo nivel que el piso \#4. Se accede al cuarto hundido por medio de una escalera ubicada en la esquina noreste.

El descubrimiento de un sistema de rampas construidas sobre el piso \#3 constituye un elemento importante para entender la secuencia de las remodelaciones (Fig. 3). En particular, se entiende la función de dos sistemas de rampas superpuestos así como el acceso a una banqueta al sur que debería corresponder al nivel del piso \#2. La interpretación de estas rampas está ligada a la probable existencia de una estructura elevada en la esquina suroeste o de una banqueta que formaba el límite sur de esta antigua organización espacial.

Como se ha mencionado anteriormente, los pisos \#3 y \#4 así como la arquitectura asociada con ellos son de filiación Moche. No existe ningún indicio de arquitectura 
de la cultura Gallinazo asociada con los pisos \#3 o \#4. Debajo del piso \#4, al sur del muro de contención al cual están adosadas las rampas antes referidas, la existencia de un muro fabricado con adobes de tipo Gallinazo sugiere una presencia muy débil de este grupo cultural. Sin embargo, en las capas de relleno entre los pisos \#2 y \#3, entre los pisos \#3 y \#4, y en particular debajo del piso \#4, la identificación de cerámica doméstica Gallinazo es frecuente. Debajo del relleno sobre el cual se construyó el piso \#4 se encuentra una capa de arena que corresponde al estéril en este sector del sitio.

Para concluir, se puede afirmar que la planificación de la plaza implicó el relleno de las construcciones asociadas con el piso \#3 y la inmediata construcción del piso \#2. La organización espacial de la primera fase constructiva es diferente de la segunda, pero el carácter administrativo y religioso parece mantenerse. El cuarto hundido podría haber sido un lugar sagrado. Durante nuestras excavaciones notamos que el relleno que lo cubría estaba particularmente limpio, lo cual indica un especial cuidado para su tapado. Las tres sepulturas se encontraron inmediatamente al sur del cuarto hundido, relacionadas con la última remodelación del piso \#3 que está en asociación directa con el cuarto hundido. Es posible que los entierros hayan estado asociados al evento de relleno de este singular cuarto hundido, pero no tenemos elementos que nos permitan probar esta idea.

Sin embargo, no cabe duda que las tres sepulturas están asociadas con el relleno total de la primera fase constructiva para permitir la construcción de la gran plaza. El individuo de la tumba \#4 está ubicado directamente sobre el piso \#3. En la sepultura $\# 5$, el individuo fue colocado encima de la sepultura \#6, cuya fosa corta el piso \#3. El tejido materia de este artículo, decorado con una escena de cosecha de yuca, proviene de la tumba \#5 que describimos a continuación.

\section{1. La tumba \#5}

La primera sepultura hallada en esta área fue la tumba \#4 y poniendo al descubierto el piso \#3 hacia el este, dentro de la unidad de excavación G3 encontramos la tumba \#5, que corresponde al entierro de un niño, cuyo cuerpo había sido enfardado, la cabeza envuelta con un tejido amarrado a la altura del cuello, y los pies colocados sobre un adobe, el mismo que estaba envuelto por otro tejido (Figs. 4 y 5). La orientación este-oeste del esqueleto y la ubicación de la cabeza al oeste corresponden a un patrón típico Moche en el valle de Santa. La ausencia de vasijas está compensada por la presencia de tejidos típicos de estilo Moche.

El esqueleto presenta un excelente estado de conservación, faltando solamente algunos huesos pequeños de las manos y de los pies, así como algunas vértebras. Por la calcificación de los dientes temporales, podemos afirmar que el individuo tenía 3 años al momento de su muerte, pero es imposible determinar el sexo (Gagné, 2003). El cráneo fue deformado artificialmente de adelante hacia atrás. La deformación parece estar asociada con un comienzo precoz de sinóstosis de la sutura coronal. No hay ninguna patología en los huesos del niño. Todos los dientes temporales están presentes en los dos arcos y ningún diente permanente había brotado. El desgaste es débil, pero en los incisivos presenta algunos puntos con la dentina expuesta. No hay microfracturas. 


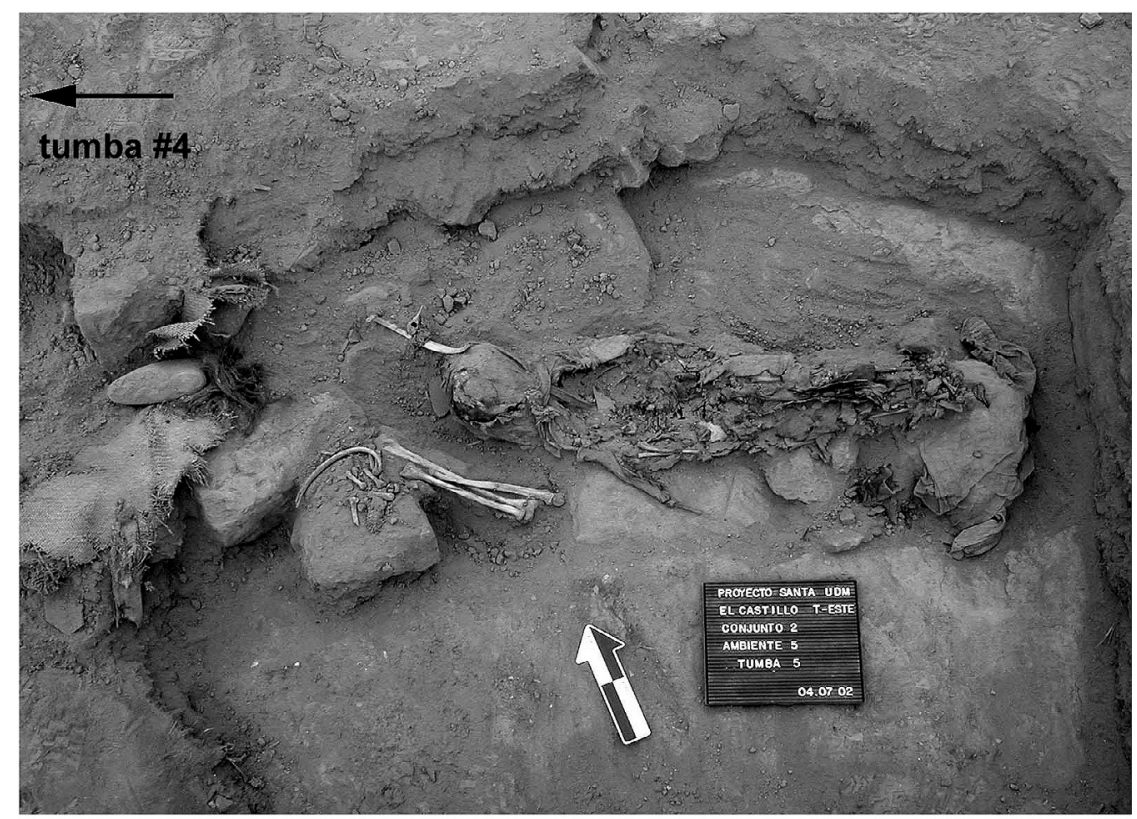

a)

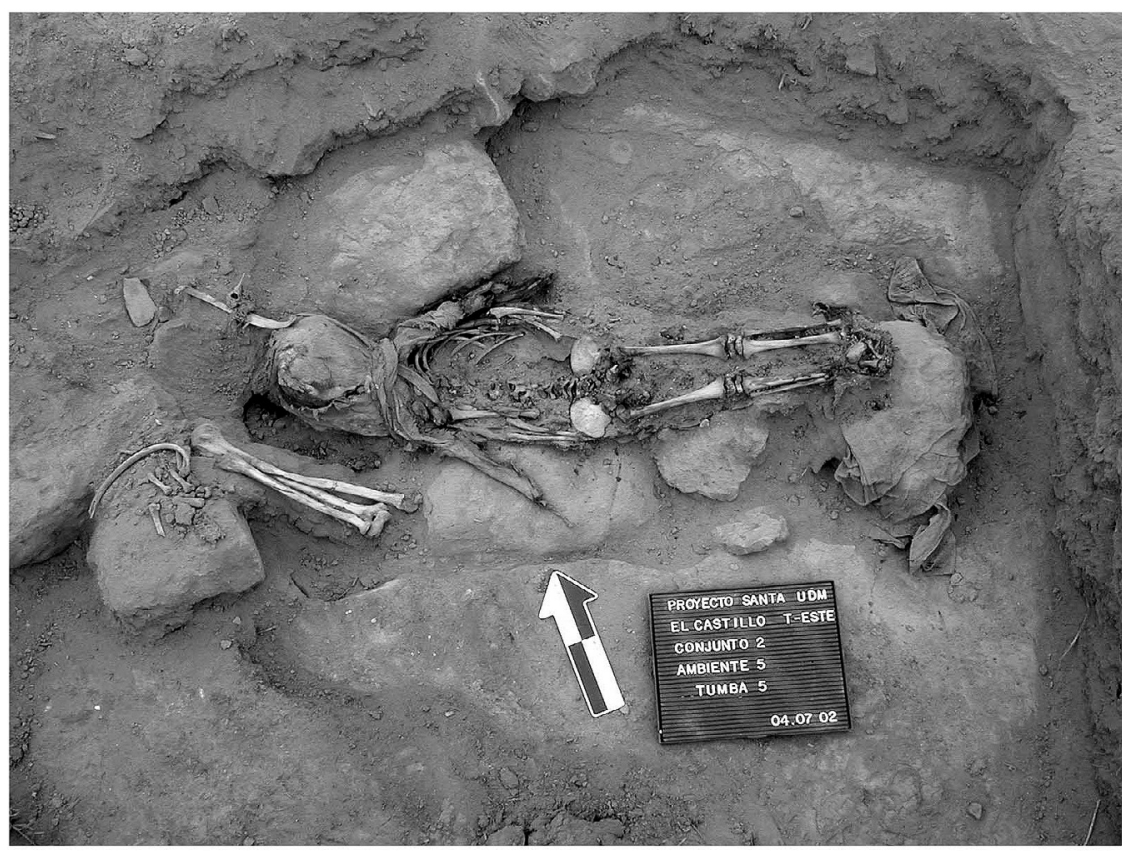

b)

Fig. 4 - Tumba \#5: a) primera etapa para delimitar el entierro; b) segunda etapa hasta la limpieza del esqueleto. 


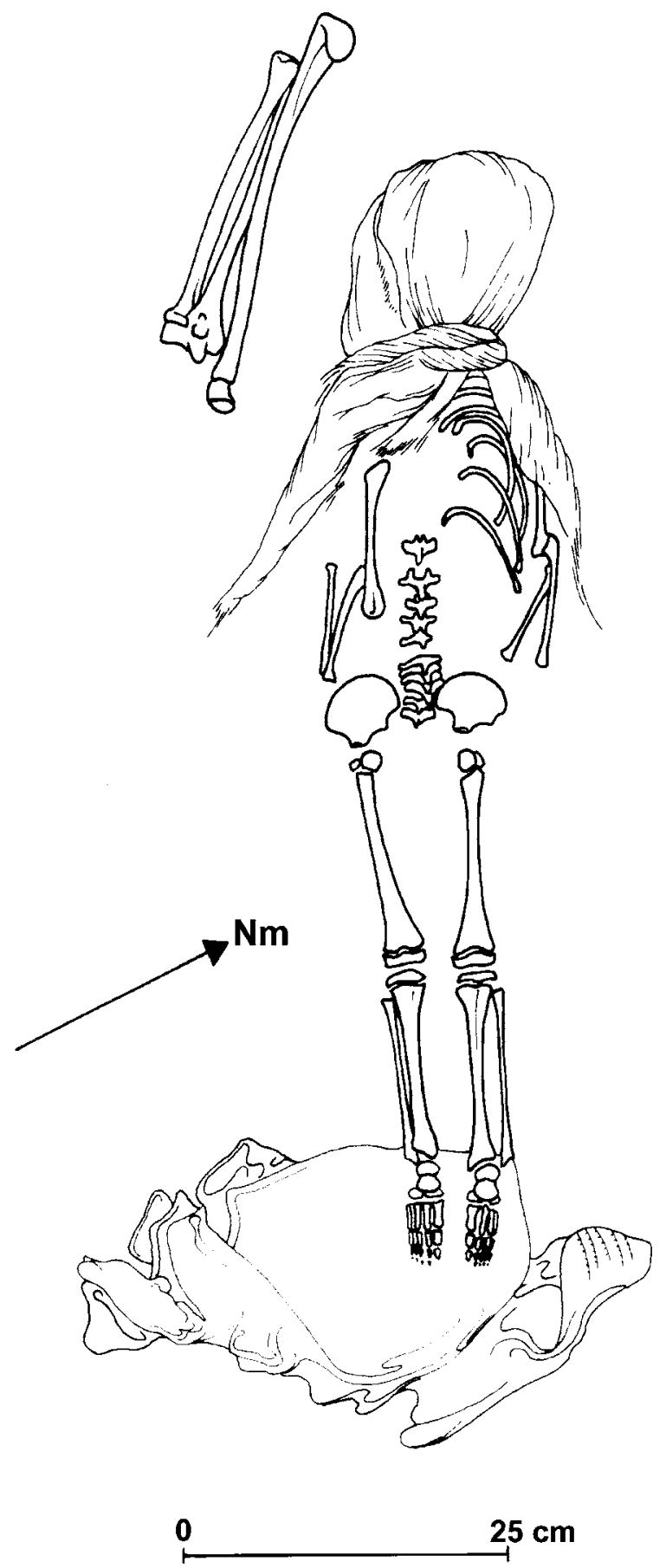

Fig. 5 - Plano de la tumba \#5. 
Los dos incisivos laterales superiores presentan sin embargo signos de caries circular. Esta patología está asociada con un defecto de calcificación del esmalte. A pesar de todos los indicios disponibles, es imposible determinar la causa del deceso a partir de los restos óseos.

Al suroeste de la cabeza, dentro del relleno, se encontraron los huesos de un adulto. Identificamos el húmero, el radio y el ulna derechos, así como dos costillas derechas y la mano derecha momificada. Estos huesos son robustos y podrían pertenecer a un individuo de sexo masculino. El examen de la extremidad de una de las costillas permite atribuir a este hombre una edad de entre 16 y 22 años (Gagné, 2003). A pesar de encontrarse muy cerca de la cabeza del niño y al mismo nivel dentro el relleno, no se puede aseverar que estos huesos fueran ofrendas al niño. Podrían también pertenecer al relleno.

\section{2. El ajuar funerario}

Al terminar la limpieza para delimitar la sepultura, se pudo observar que el esqueleto estaba completamente envuelto por tejidos fragmentados (Fig. 4a) y que no había ofrenda cerámica alguna al exterior del fardo. Después de retirar los tejidos fragmentados que cubrían los huesos (Fig. 4b), se confirmó la ausencia de cerámica. Recuperamos una aguja de cobre y 8 tejidos de esta tumba. La aguja mide 7,5 $\mathrm{cm}$ de largo, tiene un diámetro de $1,6 \mathrm{~mm}$ y su ojo menos de $0,5 \mathrm{~mm}$. Se encontró mezclada con los tejidos que fueron retirados durante la primera etapa.

\section{3. Los tejidos}

Los tejidos provenientes de la tumba \#5 fueron sometidos a una limpieza mecánica y al correspondiente análisis tecnológico. Cuatro tejidos están decorados (ECE.365, ECE.366, ECE.367 y ECE.368) y cuatro de ellos no presentan decoración. El tejido que envolvía el craneo es sin decoración y el otro tejido no decorado a la altura del cuello (ECE.367) podría ser una especie de cinturón $(4,5 \mathrm{~cm}$ de ancho por $20 \mathrm{~cm}$ de largo). El tejido decorado que cubría el adobe donde estaban apoyados los pies del niño (ECE.368) es una tela rectangular de tejido llano (1 x 1) con decoración de tapiz ranurado en dos esquinas de un mismo lado, en forma de bandas alternadas de colores rojo, rosa y beige (Fig. 6). Este tejido completo tiene $44 \mathrm{~cm}$ de ancho por $58 \mathrm{~cm}$ de largo.

El análisis de estos tejidos está aún en proceso, pero dos de ellos merecen nuestra especial atención. Ambos provienen de la sección central del entierro y su decoración no se podía definir al momento de la excavación, siendo su descubrimiento en el laboratorio. El espécimen ECE.365 está fragmentado y la parte conservada mide $7 \mathrm{~cm}$ de ancho por $35 \mathrm{~cm}$ de largo (Figs. 7 y 8). Su decoración corresponde a un motivo central que se repite varias veces. Su identificación es difícil, pero se trata con seguridad de un animal estilizado. Comparándolo con otros motivos en tejidos Moche, se puede proponer que este animal estilizado es parecido al motivo geométrico en forma de cangrejo que decora un fragmento de tejido procedente de Pampa de los Incas, en el valle de Santa (Conklin, 1979: 171, fig. 9). En cada lado del motivo principal se reconoce una fila de cabezas 

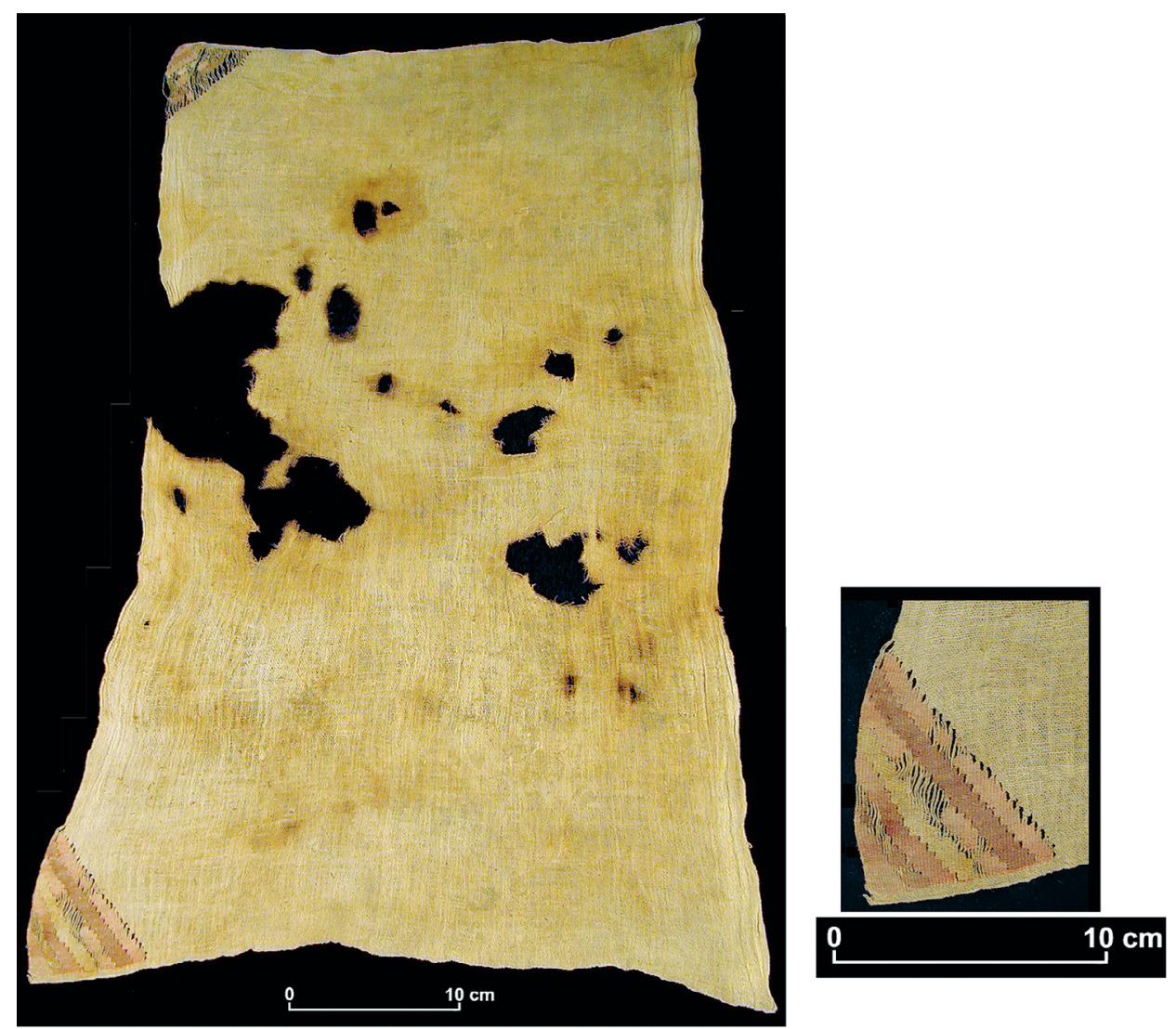

Fig. 6 - Tejido ubicado al pie del individuo.

estilizadas de ave. Es imposible determinar cuál es la especie que está representada, pero por la forma pronunciada del pico, consideramos que se trata de un ave marina. Dentro esta perspectiva, la asociación cangrejo-ave marina parece lógica. El pequeño tejido de la figura 7 tiene el mismo número de catálogo pero pertenece a otro textil. La decoración geométrica forma una serie de escalones.

El espécimen más impresionante y que llamó poderosamente nuestra atención (ECE.366) corresponde a un fragmento de tapiz ranurado. La tela recuperada mide $22,5 \mathrm{~cm}$ de ancho y $27 \mathrm{~cm}$ de largo. Está compuesta por una banda angosta de tela llana de algodón ( 1 x 1) a la cual está cosido un tapiz decorado. A pesar que el tapiz presenta dos orillos que forman la esquina inferior derecha, no es posible determinar las medidas originales, como tampoco la forma que tuvo el tejido (Figs. 9 y 10). Las fibras textiles utilizadas son algodón con torsión en $\mathrm{S}$ en el caso de las urdimbres, y lana con torcido en $\mathrm{Z}$ para la trama. Las diferentes áreas de colores que conforman los diseños cursivos se separan mediante líneas de contorno formadas por hilos de color beige. Los colores predominantes son el rojo y el beige; este contraste recuerda el uso de la técnica bicolor sobre la cerámica pintada Moche. 


$$
\text { [1] }
$$




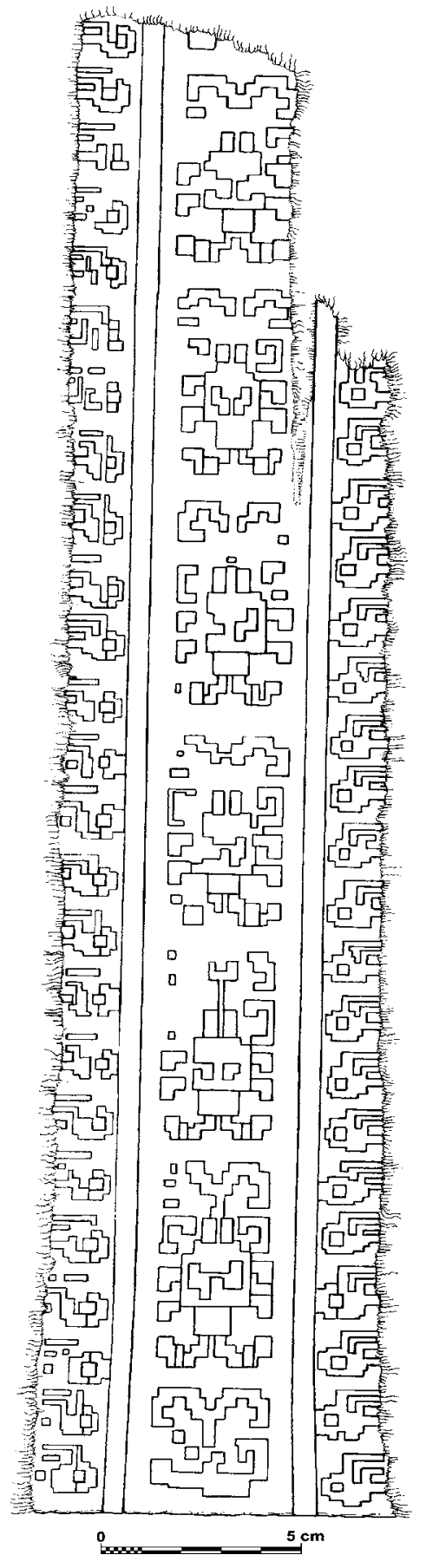

Fig. 8 - Dibujo del tejido con el animal geométrico (¿cangrejo?) y con las cabezas de ave (dibujo de Jorge Gamboa Velásquez). 


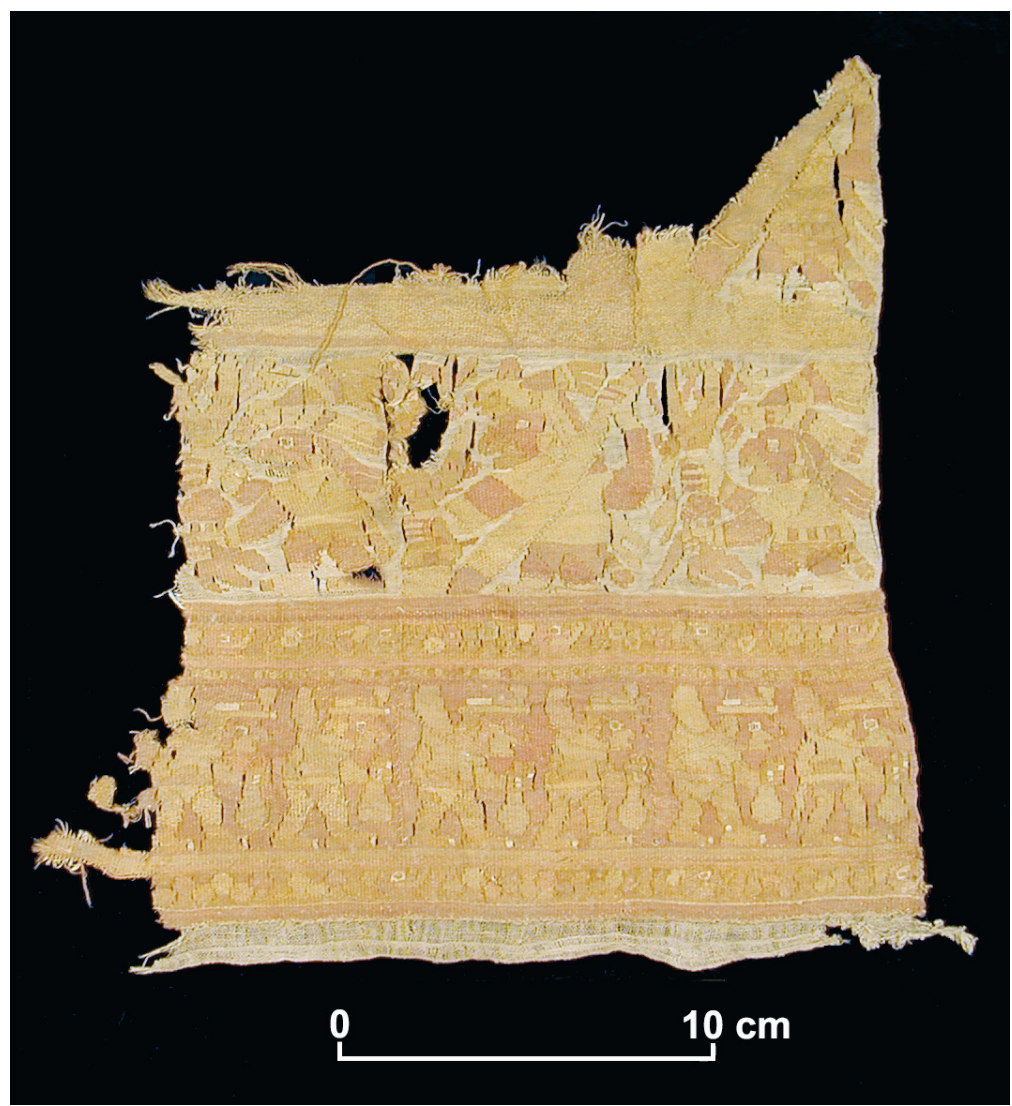

Fig. 9 - Tejido con la escena de cosecha de la yuca.

El tapiz representa escenas complejas de estilo cursivo y también figuras de estilo geométrico, distribuidas en por lo menos cinco bandas horizontales. En la primera banda están representadas las figuras geométricas en forma de serpientes que se dirigen de izquierda a derecha. El motivo decorativo es similar al representado en un tejido encontrado en Pacatnamú (Ubbelohde-Doering, 1983: 83 y 133). La segunda banda está decorada con una escena compleja en la cual aparecen seis personajes de perfil, que caminan hacia la derecha. Sostienen una bolsa con la mano izquierda y llevan un fardo en la espalda. Los personajes presentan rasgos similares, excepto el primero a la derecha, que se distingue por tener un cinturón. No es posible precisar el tipo de actividad que realizan los personajes descritos, pero por la posición encorvada del cuerpo y la bolsa que llevan, es sugestiva la idea que la escena aluda a una faena de siembra, sirviendo las bolsas para transportar semillas. Los seis personajes presentan tocado sencillo con una figura de forma triangular escalonada invertida. En la tercera banda decorada se repiten las figuras geométricas en forma de serpiente, pero con el cuerpo más corto. Se dirigen también hacia la derecha. Cuatro de ellas están completas y de una quinta serpiente sólo aparece la cabeza. 


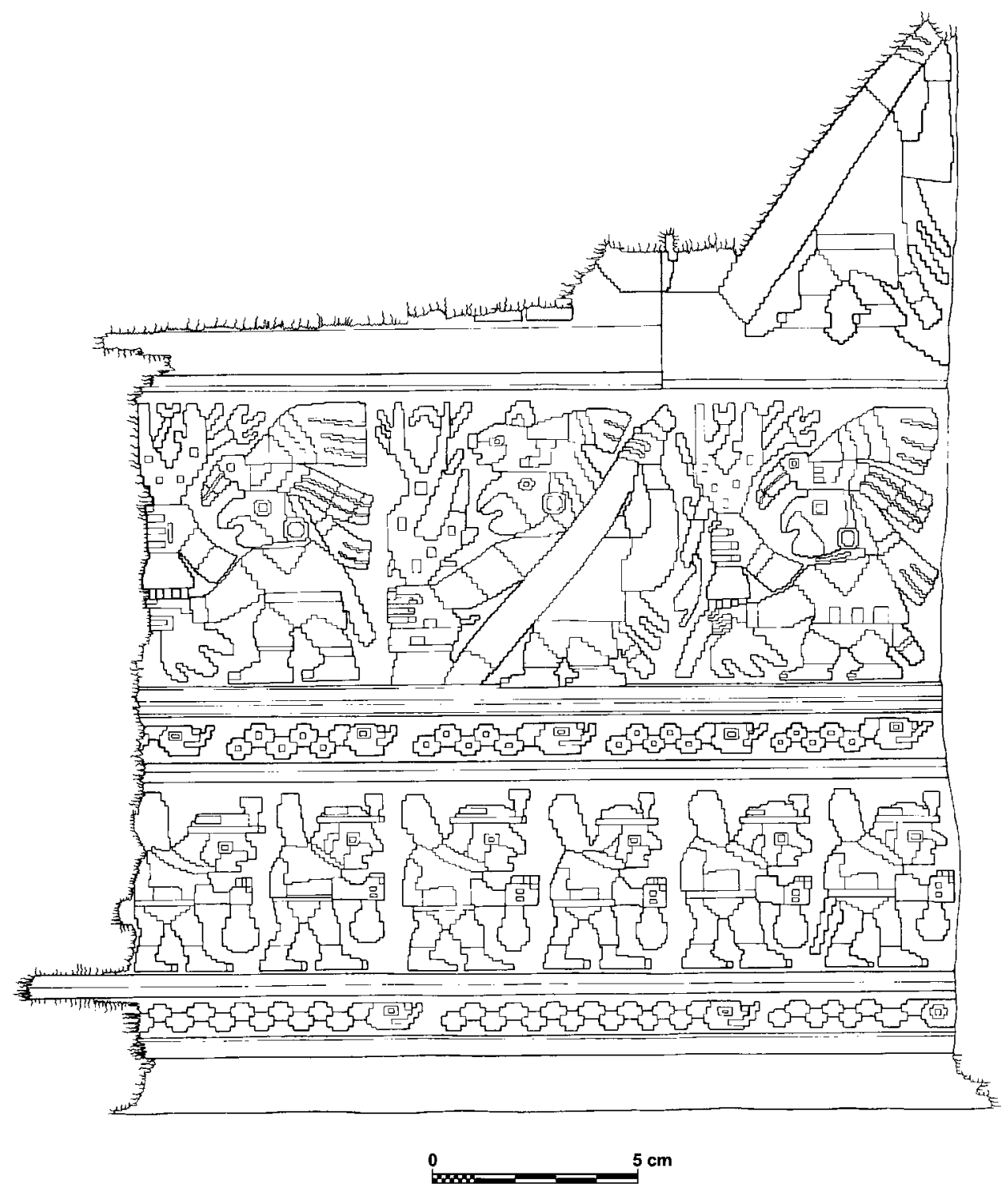

Fig. 10 - Dibujo del tejido con la escena de cosecha de la yuca (dibujo de Jorge Gamboa Velásquez). 
La escena central del tapiz se desarrolla en la cuarta banda, encima de las serpientes. Los tres personajes representados en esta banda participan de la cosecha de una planta identificada como la yuca (Manihot esculenta). Los tres personajes están vestidos con taparrabos y camisetas sin mangas. La camiseta del personaje central es de color entero, mientras que las camisetas de los personajes laterales están decoradas con motivos escalonados. Los tres individuos representados tienen como atavíos tocados con penacho, orejeras circulares y brazaletes. Debajo del tocado está representado el cabello largo de cada individuo. El personaje central está representado de vista frontal, pero los personajes laterales están representados de perfil. Sin embargo, las piernas de los tres personajes están representadas de perfil y se dirigen hacia la izquierda; en todos los casos sus pantorrillas están pintadas. El personaje central es el de mayor tamaño, es el único que posee un cinturón y su tocado tiene la forma de un zorro o de un felino. Con la mano izquierda está cortando la tierra con un instrumento agrícola que tiene la forma de un palo recto y largo con regatón. Con su mano derecha coge el tallo de la planta de yuca para extraerla de la tierra. La planta no presenta las raíces, pero el tallo, ramas y hojas sí están representados. Los personajes laterales son similares al personaje central, pero carecen de cinturón y el tocado que llevan tiene la forma de un ave con pico largo. A diferencia del personaje central, estos personajes no portan una herramienta agrícola y sostienen la planta de yuca con las dos manos. Las plantas representadas muestran las raíces, el tallo bifurcado, las ramificaciones, las protuberancias del tallo, así como lo que podría considerarse las hojas de la planta. La quinta banda presenta decoración únicamente en el extremo derecho. La parte decorada parece repetir la escena de la cosecha, pero aparece sólo la figura de un individuo similar al personaje central de la cuarta banda, también orientado hacia la izquierda. Una diferencia notable entre la escena de la banda anterior y esta última es que el personaje con instrumento agrícola comienza la secuencia de acciones. En este caso el instrumento no tiene regatón. El personaje está parado sobre lo que podría interpretarse como los lomos que se forman a los costados de los surcos de un campo arado.

La identificación de la planta de yuca se basa en primer lugar en los rasgos visibles, como son las raíces tuberosas comestibles y las protuberancias o partes salientes del tallo, sobre las cuales se insertan las ramificaciones. Además, en las representaciones del tejido se distinguen claramente las raíces. En segundo lugar, revisamos las representaciones de la yuca en la iconografía mochica y encontramos los mismos rasgos. En ellas se muestran las raíces comestibles y la base del tallo. Generalmente el tallo es bifurcado y muestra claramente las protuberancias donde se insertan las ramificaciones, pero no se representan las ramas ni las hojas. Sin duda la planta representada en el tejido proveniente de la Terraza Este corresponde al arbusto de la yuca. Los motivos no presentan rasgo alguno que permita confundirlos con representaciones de maíz.

La mandioca o yuca ha sido representada en diferentes contextos por los artistas Moche. Una breve revisión de la literatura permite avanzar tres contextos. El primero es la representación natural de la planta en una botella de asa estribo; vasijas de este tipo se conocen desde la fase Moche II (Larco, 2001 t. I: 269, fig. 316; Berrin, 1997: 121). El segundo es la representación de las raíces comestibles de la yuca en su forma natural, de las cuales emerge un personaje antropomorfo con colmillos (Larco, 2001 t. II: 288, fig. 304; Donnan, 1978: 153, fig. 234; Bruhns, 1994: fig. 12.10). El tercero 
es la representación de un hombre con o sin colmillos en asociación con las montañas (Hocquenghem, 1987: fig. 166 y fig. 167; Donnan, 1978: 144, fig. 222), con el arco terminado por cabezas de serpientes (ver Fig. 12 de este artículo) o aureolado con estrellas (Larco, 2001 t. I: 257). Estas variantes están siempre representadas en vasijas escultóricas; el personaje empuña con una mano una planta de maíz y con la otra una planta de yuca. Son rasgos dominantes de las representaciones de yuca las raíces en número de cinco, el tallo bifurcado, así como la presencia de protuberancias sobre las cuales se insertan las ramificaciones.

Los tejidos constituyen sin duda uno de los medios más importantes para las expresiones artísticas de los mochicas (Donnan \& Donnan, 1997). A pesar de no ser tan numerosos como los objetos de cerámica, los tejidos decorados que se han conservado ponen de manifiesto un arte plenamente elaborado en el cual se expresan generalmente una iconografía compleja y detallada (Donnan, 1978: 20). El hallazgo del tejido decorado con escenas agrícolas reviste gran importancia para el estudio de la iconografía mochica y el entendimiento de la economía agraria de esta civilización. En primer lugar, se trata de la primera representación iconográfica de la planta de la yuca sobre un tejido. La representación en estilo cursivo ilustra la forma real y sin estilización de la planta, logrando que su identificación sea muy clara a primera vista y que el mensaje se capte fácilmente en la primera lectura. En segundo lugar, se trata de la primera representación de actividades agrícolas al excepción de una representación sobre un bastón de madera del sacerdote-guerrero de Huaca de la Cruz (Strong \& Evans, 1952). Las escenas descritas en el tejido amplían el abanico de temas hasta ahora conocidos de la iconografía mochica (Donnan, 1991: 269). La evocación de faenas agrarias en la iconografía confirma la importancia que estas actividades cumplían en la vida cotidiana y la economía mochica, pero más importante aún es que revelan el carácter ritual que estas actividades tenían, en particular el cultivo de la yuca. En tercer lugar, la representación de las escenas agrícolas en el tejido procedente de un contexto funerario Moche III de la Terraza Este del sitio El Castillo contradice una afirmación anterior según la cual los tejidos Moche III sólo representan animales o animales míticos, pero no figuras humanas (Conklin, 1979: 182). Por otro lado, las representaciones de serpientes de este tejido así como las representaciones de cangrejo en otro tejido proveniente del mismo contexto funerario (espécimen ECE.365) comprueban la antigüedad de los diseños geométricos en tejidos de la fase Moche III (Conklin \& Versteylen, 1978). Finalmente, no está de más señalar que el estilo de los diseños en el tejido de la Terraza Este es bien diferente del estilo Moche-Huari reconocido en el sitio El Castillo del valle de Huarmey (Prümers, 1989; 2000).

Esta breve descripción de las características decorativas y estructurales de los tejidos de la tumba \#5 se suman a la confirmación de la existencia de una tradición artística avanzada en la fase Moche III, durante la cual comienzan a desarrollarse representaciones en perspectiva y a representarse figuras de perfil (Donnan \& McClelland, 1999: 292). En el tejido con las escenas agrícolas, las acciones se representan en por lo menos cinco campos horizontales, siendo posible que formen distintos planos horizontales bidimensionales a diferentes distancias del observador (Donnan, 1978: 33). Sin embargo, no hay que olvidar que la técnica de campos horizontales utilizada por los Moche para obtener profundidad de campo puede implicar el sincronismo o simultaneidad de las acciones representadas, como también la representación de un 
conjunto de acciones relacionadas entre sí y que se suceden unas a otras. En tal sentido, por el momento resulta difícil evaluar si es que todos los campos horizontales del tejido de Terraza Este representan acciones que se realizan en un mismo momento, si es que describe una serie de acciones que se suceden unas a otras a intervalos cortos de tiempo, o si narra acciones que se realizan a intervalos de tiempo más largos.

Antes de entrar en más detalles respecto de la significación de este singular tejido, presentamos una descripción de las otras tumbas asociadas, luego de lo cual se discutirá sobre las implicaciones del cultivo de la yuca en la economía Moche.

\section{UN PATRÓN FUNERARIO}

Como mencionáramos antes, la tumba \#5 se encuentra al mismo nivel que la tumba \#4 y fue depositada directamente sobre el entierro \#6 (Fig. 3). Si las tres tumbas están asociadas, pertenecen a un patrón funerario distinto del que conocemos en la Terraza Norte en el sitio El Castillo. En la Terraza Norte excavamos en 2001 dos sepulturas de miembros de la elite Moche del sitio (Chapdelaine \& Pimentel, 2002). Las sepulturas estaban parcialmente saqueadas y su ajuar funerario compuesto principalmente por numerosas vasijas. Ambas sepulturas estaban ubicadas al interior de un sector administrativo. Una de ellas corresponde a una cámara de adobes de gran tamaño; la otra sepultura se encontraba debajo de un piso de la primera fase constructiva, dentro de una capa de relleno que cubre las construcciones de la segunda fase. Las sepulturas pertenecían a individuos adultos, cuyos cuerpos fueron colocados al interior de un sarcófago fabricado con cañas (para más detalles invitamos los lectores a leer los informes disponibles en la pagina web del primer autor: www.mapageweb. umontreal.ca/chapdelc). Contrariamente, las tres tumbas de la Terraza Este Baja no contenían ofrendas de cerámica. La ausencia de ofrendas de cerámica en entierros Moche ya ha sido documentada en el valle de Santa (Donnan, 1973: 132-135), en tal sentido la ausencia de este tipo de ofrendas en las tres sepulturas de Terraza Este Baja no constituye una sorpresa. La gran cantidad de fragmentos de vasijas de cerámica que se encuentra en la superficie de los cementerios visitados durante los tres últimos años nos permite sugerir que la mayoría de los entierros Moche debió contener vasijas. Sin embargo, apoyándonos en los datos de los entierros por nosotros excavados, parece ser que la costumbre de ofrecer ceramios no fue seguida de manera tan rigurosa en el valle de Santa. Este patrón funerario sin ofrendas de cerámica en la Terraza Este Baja podría corresponder a un acontecimiento especial relacionado con el relleno de una fase constructiva para elaborar una nueva organización espacial. No se puede establecer fácilmente el estatus de los individuos enterrados, pero los tejidos que estaban asociados a ellos indican sin duda que los cuerpos fueron preparados con especial atención. Al individuo más joven se le ofrendaron algunos tejidos decorados, entre ellos el tapiz que representa una escena hasta ahora desconocida que ilustra la cosecha de la yuca en la que participan personajes importantes.

\section{1. La tumba \# 4}

Buscando el piso \#3 en la unidad G2 encontramos la tumba \#4 (Figs. 3 y 11). Aunque no hubo vasija asociada al difunto, el estilo de los tejidos permite atribuir la tumba a la cultura Moche. Dentro del relleno se recuperó una aguja de cobre similar 

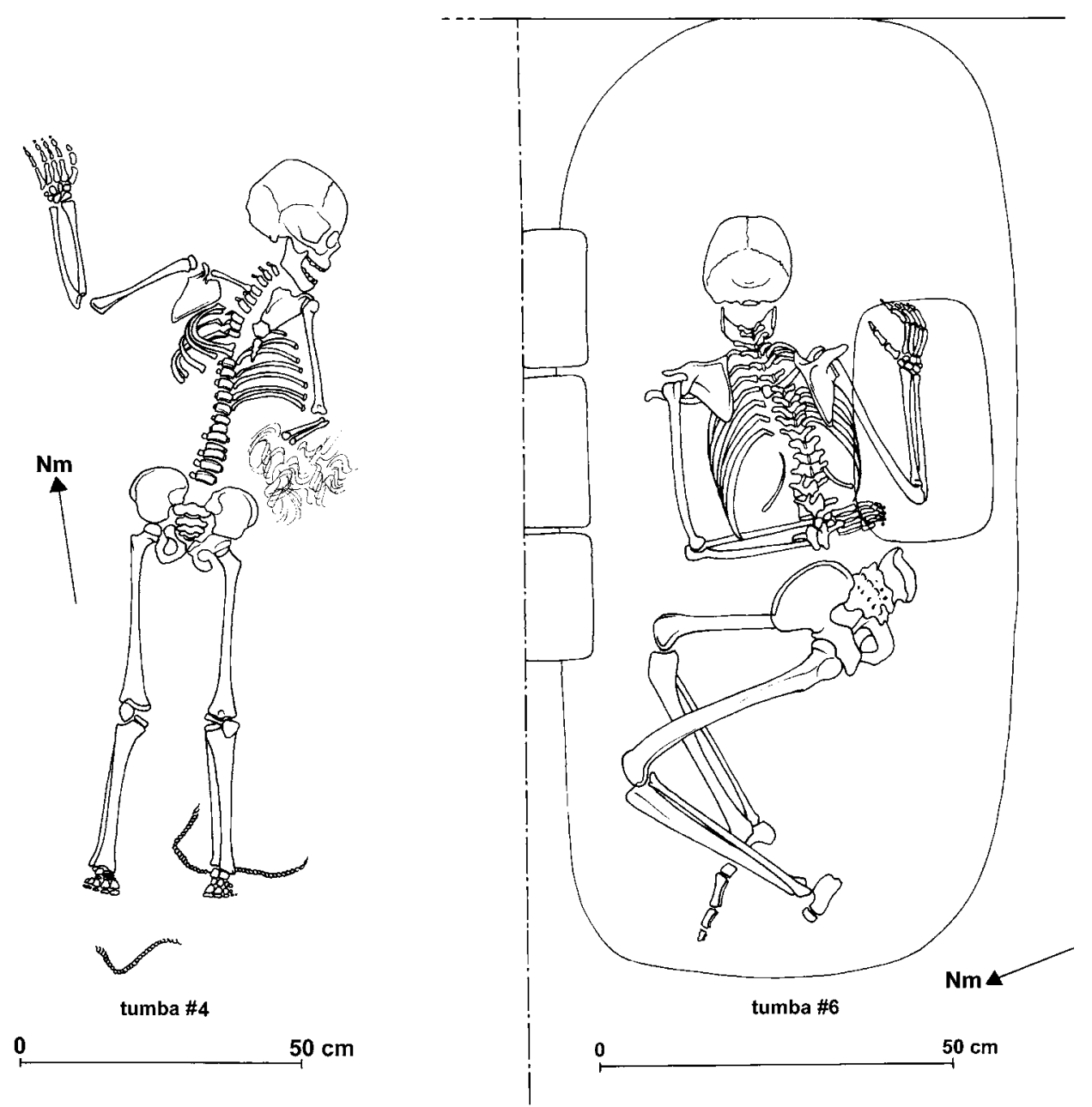

Fig. 11 - Plano de las tumbas \#4 y \#6.

en forma y dimensiones a la encontrada en el entierro \#5 (largo: 5,8 cm, diámetro: 1,4 $\mathrm{mm}$ y el ojo 0,54 $\mathrm{mm}$ ) así como una concha perforada de Prunum curtum.

El cuerpo del difunto fue colocado en posición decúbito supino o dorsal, orientado de norte a sur, con la cabeza en el lado norte y el rostro mirando hacia el este; su brazo derecho estaba levantado hacia la cabeza y doblado en ángulo de 90 grados (Fig. 11). Había restos de soguillas a la altura de los pies, un paquete de lana en su mano izquierda y un tejido no decorado cerca de su mano derecha. El esqueleto del individuo está bien conservado y casi completo, faltando sólo el hueso hioides y algunos huesos de 
los pies; el sacro está parcialmente roto. Por el grado de calcificación y la erupción dental se puede establecer que el individuo tenía entre 9 y 10 años (Gagné, 2003). La calcificación de la primera y de la segunda molares temporales, de la segunda molar permanente, así como de la primera premolar indican una edad de aproximadamente 9 años. Los caninos ya habían brotado y eran funcionales, lo que indica una edad máxima de 10 años. No se puede determinar el sexo y tampoco había patología alguna. En cuanto a la dentadura, no hay pérdida ante mortem, el desgaste oclusal es muy débil o casi inexistente, y tres dientes están cariados: las dos primeras molares temporales del maxilar, y la segunda molar temporal en la mandíbula.

\section{2. La tumba \#6}

Debajo de la tumba \#5, al interior de una fosa que corta el piso \#3, se encontró una tercera sepultura, que denominamos tumba \#6 (Figs. 3 y 11). Se trata del entierro de un hombre adulto, cuyo cuerpo fue dispuesto con orientación este-oeste, con la cabeza ubicada del lado este y con el rostro dirigido hacia el suelo. Por su posición estratigráfica, estamos seguros de la asociación entre la tumba \#5 y la tumba \#6. No hubo ofrendas de cerámica, sin embargo los tejidos asociados al individuo de esta sepultura son de estilo Moche. Encontramos además dos conchas perforadas de Prunum curtum, cada una atada a un hilo de algodón.

La parte superior del cuerpo fue colocada decúbito prono, es decir que el cuerpo yacía sobre el pecho y el vientre. Las piernas estaban plegadas a 90 grados y ligeramente colocadas hacia el lado izquierdo (la pierna izquierda sobre la derecha). El fémur pasa por encima del tercio proximal de la tibia derecha. Los pies estaban estirados. El brazo izquierdo bordeaba el costado de la caja torácica y el antebrazo izquierdo estaba flexionado en 90 grados sobre el estómago. La mano estaba abierta con la palma apoyada sobre el estómago. El brazo derecho estaba estirado y el antebrazo se había colocado bajo un adobe, flexionado hacia la cabeza. La mano estaba abierta y la palma apoyada contra el suelo.

El esqueleto está casi completo y sólo faltan algunos pequeños huesos de las manos y de los pies. Las suturas craneanas muestran varios espacios de fusión. El examen de las costillas indica que se trata de un individuo cuya edad variaba entre $35 \mathrm{y}$ 55 años (Gagné, 2003). Por el contrario, las modificaciones de la superficie de la sínfisis pubiana indican que este individuo tenía entre 40 y 50 años. A pesar de esta edad, los dientes (segunda y tercera molares) presentan poco desgaste. El examen de la pelvis permite definir que se trataba de un individuo de sexo masculino. En general los huesos son esbeltos y gráciles. Las tuberosidades o éntasis donde se fijan los músculos son poco pronunciadas. El tendón de Aquiles comenzaba a calcificarse en los dos calcáneos. El cráneo es relativamente alargado y presenta una ligera protuberancia, sin embargo no existe deformación craneana. La estatura de este hombre es de $157,0 \mathrm{~cm}$ si se toma la medida promedio del largo de las tibias y de los fémures por separado, pero es de $158,8 \mathrm{~cm}$ si se toman estos mismos huesos simultáneamente. En cuanto a patologías de este individuo al nivel del esqueleto, se observa que dos de los tres huesos cuneiformes del tarso presentan signos de artrosis en la superficie anterior. Las falanges dístales de los dedos pequeños de los pies están fusionados en la mediana. La columna vertebral 
presenta evidencias de osteofitosis en la sexta, sétima y octava vértebras dorsales. La duodécima vértebra tiene algunas áreas de porosidad en las depresiones. Hay igualmente osteofitosis en la quinta vértebra lumbar, mientras que las cuatro primeras están exentas de esta patología. En cuanto a la dentición, los 32 dientes permanentes están presenten en los arcos mandibulares. El desgaste de las superficies oclusales es débil o mediana en las últimas molares (segunda y tercera). Por el contrario, los dientes anteriores están muy desgastados, lo que ha provocado la destrucción casi total de las coronas. No existen caries ni hiploplasías del esmalte. Por otro lado los tabiques interdentales están fuertemente inflamados. Los tejidos de soporte de los dientes muestran un grado de severidad debido a la presencia de seis bolsas peridentales. Sin embargo, es imposible determinar las causas del deceso de este individuo.

Las tumbas \#4, \#5 y \#6 son intrusivas y posteriores al piso \#3. La inhumación de los individuos se hizo al momento de iniciarse cambios importantes en la configuración arquitectónica de esta parte de la Terraza Este, con la construcción de la Plaza. No es posible explicar el entierro de un niño sobre la sepultura de un hombre adulto maduro, cuyo cuerpo yacía contra el suelo. Tampoco es posible precisar por el momento si los dos individuos pertenecían a una misma familia. Es posible sugerir que el individuo adulto ocupaba un puesto de nivel bajo. No existen huellas visibles que nos permitan determinar las causas del deceso del individuo adulto. Si la muerte -natural o intencional- de este hombre ocurrió al mismo tiempo que el deceso del niño, también cambió el rol que desempeñaba en vida, convirtiéndose así en acompañante y guía para el niño en el otro mundo. El tejido decorado con la escena agrícola le confiere una particular importancia al niño, heredero de un cierto estatus al momento de su nacimiento. Su entierro está posiblemente relacionado con la costumbre mochica de cubrir los monumentos para construir uno nuevo, haciendo de este evento una ocasión propicia para enterrar a miembros importantes de la sociedad, dentro de la perspectiva de renovar el poder o el orden social (Uceda, 1997). En este contexto, seguimos nuestra reflexión sobre la importancia de la yuca en la economía Moche.

\section{LA YUCA EN LA ECONOMÍA MOCHE}

La mandioca o yuca (Manihot esculenta), una planta de la familia de las Euforbiáceas cuya raíz tuberosa es comestible, fue importada desde los trópicos a la costa norte del Perú en tiempos muy tempranos (Ugent et al., 1986). Es difícil establecer su origen preciso, pero parece provenir de la cuenca del Amazonas en Brasil, y su variabilidad podría inclusive ser el resultante de la domesticación de una misma subespecie de acuerdo a los últimos trabajos en genética (Olsen \& Schaal, 1999; 2001). $\mathrm{Su}$ fecha de ingreso en la economía de la costa norte es todavía materia de discusión. La dificultad de recuperar restos de esta planta y su conservación diferencial constituyen dos factores determinantes. Sin embargo, su presencia ha sido documentada en Los Gavilanes, un sitio del Período Precerámico ubicado en el valle de Huarmey (Bonavia, 1982).

Su presencia no es más frecuente entre los restos orgánicos de sitios del Período Inicial, pero es posible creer que su representación en ceramios del Horizonte Temprano constituya un indicio indiscutible de la importancia que esta planta tuvo desde entonces en la economía de las poblaciones agrícolas de los valles costeños (Alva, 1986; Berrin, 
1997: 83). En este sentido, no es sorprendente constatar que la yuca se menciona en todas las descripciones generales de la economía Moche del Período Intermedio Temprano (Bawden, 1996; Donnan, 1973; Moseley, 1992; Wilson, 1988; 1999). Sin embargo, no es fácil la identificación de la yuca en los sitios arqueológicos, debido a que no deja muchas huellas, en la medida que sus raíces son consumidas. Su ausencia en sitios como Pacatnamú (Gumerman, 1997) y Pampa Grande (Shimada, 1994) se explica en parte debido a la mala conservación. Es la misma explicación que prevalece en el sitio Huacas de Moche. Las excavaciones de sitios Moche en la parte baja del valle de Santa han proporcionado una gran cantidad de restos orgánicos que hasta la fecha no han sido estudiados por un especialista. Pero al igual que Donnan (1973: 121), hemos podido reconocer evidencias de la planta de mandioca o yuca. Sin embargo, los restos de maíz siguen siendo siempre los más numerosos.

Por cierto, no es con ayuda de la cuantificación de los restos de plantas cultivadas recuperadas en los sitios arqueológicos que podemos verdaderamente evaluar la importancia de la yuca. Cuando la conservación es buena, los restos de maíz son casi siempre dominantes. No hay más que un paso que varios investigadores han dado para considerar que el maíz fue el alimento de base de la economía Moche (Bawden, 1996 : 89). Por cierto podemos considerarla esencial, como Shimada (1994: 182-183), o como una de las principales plantas cultivadas al mismo nivel que los fríjoles, la calabaza, el ají, la palta, la yuca y el camote (Wilson, 1999: 384), pero seguramente el lugar del maíz no es el mismo que las poblaciones mesoamericanas le acordaron a esta planta (Bruhns, 1994: 89). Sabemos históricamente que una parte de la producción del maíz era transformada en bebida fermentada: la chicha. La importancia ceremonial de esta planta fue traspuesta a la época remota de los Moche, pero no podemos olvidar que las sociedades amazónicas preparaban también una bebida a partir de la yuca. Ignoramos completamente si los Moche adoptaron esta receta que podía completar aquella del maíz, pero las numerosas vasijas conocidas como rayadores, que presentan incisiones profundas, han sido interpretadas como artefactos para rayar la yuca, con la finalidad de preparar harina.

Aceptando la idea que la yuca ocupó un lugar particular en la economía agraria Moche, son pocos los estudios que se han realizado con el objeto de dilucidar su importancia en el campo alimenticio y económico considerando que su poco cargado en proteínas no es compensado con su riqueza en calorias (Roosevelt, 1980: 124-128). Al igual que los artistas Cupisnique, los artesanos Moche modelaron también la yuca en soportes de cerámica. Algunos ejemplos que datan incluso de la fase estilística Moche II, pueden servir de fundamento para señalar la importancia relativa que tuvo la yuca desde épocas bien tempranas en el desarrollo de la cultura Moche.

La yuca es una planta muy diferente del maíz. Si el maíz toma 4 meses para madurar gracias al aporte constante de agua, la yuca toma 9 meses para que sus raíces sean comestibles. Estas últimas continúan creciendo hasta los 12 meses; las raíces son entonces más grandes y gruesas, y por lo tanto son más rentables para quienes pueden esperar todo este tiempo. Se trata de una planta que ofrece una cosecha al año, pero la cantidad de alimento es más importante que aquella que se obtiene de la producción de maíz en una misma unidad de tierra cultivada.

La yuca parece desarrollarse mejor en terrenos arenosos y no conocemos 
sobre sus necesidades hídricas, aún si sabemos que el suelo debe estar húmedo. Esta planta crece muy bien en los terrenos pobres y se puede conservar meses después su maduración dentro la tierra (Roosevelt, 1980: 122-123). Durante la época Moche, habían transcurrido ya más de dos mil años desde que la yuca había sido implantada en la costa. Varios indicios parecen apoyar la idea que esta planta pudo jugar un rol alimentario importante en el marco de una expansión demográfica, como aquella registrada en el valle de Lacramarca. En este valle desértico, la principal fuente de agua en la época Moche provenía del río Santa. Un enorme canal de irrigación que se bifurcaba en la entrada al valle de Lacramarca permitió la transformación del desierto en tierras cultivables ocupadas por colonos Moche controlados a partir de un importante centro ceremonial conocido como Huaca San Pedro, situado dentro de los límites de la ciudad de Chimbote (Fig. 3). En la superficie de los sitios de este valle y en particular en el sitio Hacienda San José, se han encontrado fragmentos de vasijas que ilustran regularmente escenas relacionadas con la agricultura, donde aparecen especialmente representaciones de maní, maíz y pallares.

Durante nuestras excavaciones en el sitio Hacienda San José (Fig. 3), hallamos en la sepultura de un niño una ofrenda de cerámica consistente en un cántaro escultórico que representa una escena en la cual un personaje de pie, debajo de un arco en forma de serpiente bicéfala, empuña con su mano derecha una planta de maíz y con su mano izquierda una planta de yuca (Fig. 12). El personaje no ostenta los colmillos de los seres divinos mochicas. Esta escena se refiere al período de cosecha y a la evocación del ancestro benéfico (Hocquenghem, 1987: 157). La representación de la yuca en este contexto específico confirma la importancia de esta planta en el plano simbólico. El hecho que acompañe regularmente al maíz nos permite creer que la yuca tenía la misma importancia. Esta vasija asociada a la sepultura de un niño en Hacienda San José recuerda la tumba \#5 de Terraza Este Baja, donde el niño inhumado recibió como ofrenda un tejido que ilustra una escena de cosecha de yuca.

En consecuencia, es posible considerar que la yuca fue utilizada de manera importante en la parte baja del valle de Santa y que los investigadores deberían considerar más seriamente los estudios de la base agraria de la economía Moche. Privilegiando la idea que esta base era mucho más diversificada que aquella basada en la trilogía maíz, frijoles y cucurbitáceas, que se ha reconocido para las sociedades complejas de Mesoamérica, la yuca habría probablemente ocupado un lugar importante como el maíz en la alimentación cotidiana, teniendo en consideración que una parte de la cosecha del maíz habría servido para la producción de chicha, la bebida preferida durante la realización de numerosas ceremonias.

\section{CONCLUSIÓN}

La yuca pudo ser una planta que necesitó el control del estado expansionista Moche. En efecto, al igual que el algodón que toma más de 6 meses para estar listo, la yuca necesita 9 meses para empezar su cosecha, pero su rendimiento es mejor a partir del año. Es difícil que un agricultor haya podido esperar 9 meses en los nuevos campos de cultivo de Lacramarca sin contar con el apoyo de los dirigentes mochicas. La yuca podría haber sido la planta por excelencia, conjuntamente con el maíz y otras plantas relacionadas como el pallar y posiblemente el camote, en los proyectos de expansión 


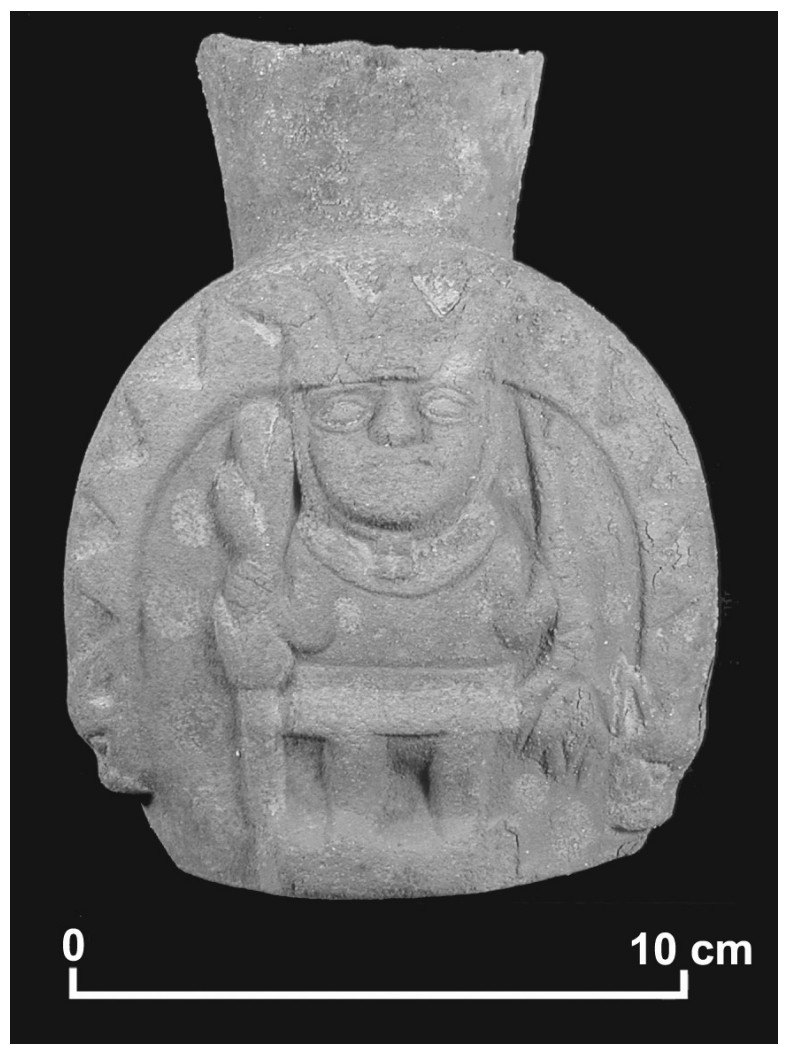

Fig. 12 - Vasija decorada con personaje que empuña las plantas de yuca y maíz, tumba del sitio Hacienda San José.

del año. Es difícil que un agricultor haya podido esperar 9 meses en los nuevos campos de cultivo de Lacramarca sin contar con el apoyo de los dirigentes mochicas. La yuca podría haber sido la planta por excelencia, conjuntamente con el maíz y otras plantas relacionadas como el pallar y posiblemente el camote, en los proyectos de expansión estatales y en la producción de bienes a gran escala.

La representación de faenas agrarias en la iconografía confirma su importancia en la vida cotidiana y la economía mochica, pero también revelan el carácter ritual que estas actividades tenían. Las escenas de cosecha de la yuca en el tejido de la tumba \#5 de Terraza Este Baja en el sitio El Castillo proporciona elementos que nos permiten revaluar la importancia que tuvo esta planta en la economía agraria de los Moche en el valle de Santa. La participación de personajes de alto rango en la cosecha de la yuca confiere a esta planta una posición de elevada importancia, en la medida que se trata de actividades que gozaron del apoyo de las autoridades. La participación de seres míticos en la cosecha de esta planta, como es el caso de la representación en la vasija asociada a la tumba de un niño en Hacienda San José no hace más que reafirmar la importancia de este cultivo. 
tener una visión más completa sobre el contenido de las sepulturas en comparación con otros sitios, como por ejemplo Huacas de Moche. Podemos de esta manera reconocer tres variantes del patrón funerario Moche en el Santa. Las sepulturas sin ofrendas de vasijas de cerámica, las sepulturas con una o dos vasijas, y finalmente las tumbas de elite con diez o más ceramios. En algunos casos, se encuentran recipientes fabricados con mate, lo que recuerda los casos documentados en las tumbas Moche de Pacatnamú (Donnan \& McClelland, 1997; Ubbelohde-Doering, 1983).

La tumba \#5 pertenece a un patrón funerario que no incluye vasijas de cerámica. El individuo tampoco recibió ofrendas de mate. El cuerpo no fue colocado dentro de un ataúd fabricado con cañas sino dentro de una mortaja que envolvía el cadáver. Sus pies fueron cuidadosamente apoyados sobre un adobe envuelto por una tela y algunos huesos de un individuo adulto fueron colocados cerca de su cabeza. Este fardo funerario fue colocado directamente sobre la sepultura de otro individuo adulto cuya cabeza y cuerpo yacían directamente sobre el suelo. Es difícil entender el significado de estas asociaciones, pero parece ser que el niño a quien se ofrendó el tejido que ilustra las escenas de cosecha de yuca no emprendió sólo su viaje al más allá. Estos comportamientos funerarios se inscriben en la renovación del poder de los dirigentes de la Terraza Este del sitio El Castillo.

\section{Agradecimientos}

Queremos expresar nuestro sincero agradecimiento a todos los miembros del Proyecto PSUM y a quienes nos brindaron su apoyo o nos asistieron de diferentes modos. El análisis de los esqueletos fue realizado por Gérard Gagné, el dibujo técnico de los tejidos fue ejecutado por Jorge Gamboa Velásquez y en la descripción técnica de los tejidos contamos con las valiosas opiniones de Delicia Regalado y France-Éliane Dumais. Hélène Bernier realizó los otros dibujos que ilustran este artículo.

\section{Referencias citadas}

ALVA, W., 1986 - Cerámica temprana en el valle de Jequetepeque, Norte del Perú, 136p.; Munchen: Materialien zur Allgemeinen und Vergleichenden Archäologie, Band 32, Verlag C. H. Beck.

BAWDEN, G., 1996 - The Moche, 375p.; London: Blackwell Publishers.

BERRIN, K., 1997 - The Spirit of Ancient Peru, Treasures from the Museo Arqueológico Rafael Larco Herrera, 216p.; Londres: Thames and Hudson.

BONAVIA, D., 1982 - Precerámico Peruano: Los Gavilanes, Mar, Desierto y Oasis en la Historia del Hombre, 512p.; Lima: Corporación de Financiera de Desarallo S.A., COFIDE \& Instituto Arqueológico Alemán, Perú.

BRUHNS, K., 1994 - Ancient South America, 424p.; London: Cambridge University Press, London.

CHAPDELAINE, C. \& PIMENTEL, V., 2001 - Informe del Proyecto Arqueológico PSUM (Proyecto Santa de la Universidad de Montreal) 2000 - La presencia Moche en el valle del Santa, Costa Norte del Perú. Lima: Informe sometido al Instituto Nacional de la Cultura, Perú, 310p. (www.mapageweb.umontreal.ca/chapdelc). 
CHAPDELAINE, C. \& PIMENTEL, V., 2002 - Informe del Proyecto Arqueológico PSUM (Proyecto Santa de la Universidad de Montreal) 2001 - La presencia Moche en el valle del Santa, Costa Norte del Perú. Lima: Informe sometido al Instituto Nacional de la Cultura, Perú, 325p. (www.mapageweb.umontreal.ca/chapdelc).

CHAPDELAINE, C., PIMENTEL, V. \& BERNIER, H., 2003 - Informe del Proyecto Arqueológico PSUM (Proyecto Santa de la Universidad de Montreal) 2002 - La presencia Moche en el valle del Santa, Costa Norte del Perú. Lima: Informe sometido al Instituto Nacional de la Cultura, Perú, 463p. (www.mapageweb.umontreal.ca/chapdelc).

CHAPDElaine, C., PIMENTEL, V., GAGNÉ, G., GAMBOA, J., REGALADO, D. \& CHICOINE, D., s.f. - Nuevos datos sobre Huaca China, Valle de Santa, Perú. Aprobado para su publicación en el Bulletin de l'Institut Français d'Études Andines.

CONKLIN, W. J. \& VERSTEYLEN, E., 1978 -Appendix 1. Textiles from a Pyramid of the Sun Burial. In: Ancient Burial patterns of the Moche Valley, Peru (Christopher B. Donnan \& Carol J. Mackey, ed.): 384-398; Austin: University of Texas Press.

CONKLIN, W. J., 1979 - Moche Textiles Structures. In: The Junius B. Bird Pre-Columbian Textile Conference (Ann P. Rowe, Elisabeth P. Benson \& Anne-Louise Schaffer, ed.): 165-184; Washington D.C.: The Textile Museum \& Dumbarton Oaks.

DONNAN, C. B., 1973 - Moche Occupation of the Santa Valley, Peru, 144p.; Berkeley: University of California Publications in the Anthropology, vol. 8, University of California DONNAN, Christopher B. \& MCLELLAND, Donna, 1997 -

DONNAN, C. B., 1978 - Moche Art of Peru, 205p.; Los Angeles : Fowler Museum of Cultural History, UCLA.

DONNAN, C. B., 1991 - La iconografía mochica. In: Los Incas y el antiguo Perú. 3000 años de historia. Tomo I: 258-270; Madrid: Sociedad Estatal Quinto Centenario.

DONNAN, C. B. \& DONNAN, S. G., 1997 - Moche Textiles from Pacatnamu. In: The Pacatnamu Papers. The Moche Occupation (Christopher B. Donnan \& Guillermo A. Cock, ed.): Vol. II: 215-242; Los Angeles: Fowler Museum of Cultural History.

DONNAN, C. B. \& MCLELLAND, D., 1997 - Moche Burials at Pacatnamu. In: The Pacatnamu Papers. The Moche Occupation (Christopher B. Donnan \& Guillermo A. Cock, ed.): 17-187; Los Angeles: Vol. II, Fowler Museum of Cultural History.

DONNAN, C. B. \& MCLELLAND, D., 1999 - Moche Fineline Painting, 319p.; Los Angeles: Fowler Museum.

GAGNÉ, G., 2003 - Los restos humanos. In: Informe del Proyecto Arqueológico PSUM (Proyecto Santa de la Universidad de Montreal) 2002 - La presencia Moche en el valle del Santa, Costa Norte del Perú (Chapdelaine, Claude, Pimentel, Victor \& Bernier, Hélène, ed.): 39-51; Lima: Informe sometido al Instituto Nacional de la Cultura, Perú. (www.mapageweb.umontreal.ca/chapdelc).

GUMERMAN, G., 1997 - Botanical Offerings in Moche Burials at Pacatnamu. In: The Pacatnamu Papers. The Moche Occupation (Christopher B. Donnan \& Guillermo A. Cock, ed.): Vol. II: 243-249; Los Angeles: Fowler Museum of Cultural History.

HOCQUENGHEM, A. M., 1987 - Iconografia Mochica, 280p.; Lima: Fondo Editorial de la Universidad Católica del Perú.

LARCO HOYLE, R., 2001 - Los Mochicas, 2 tomos; Lima: Museo Arqueológico Rafael Larco Herrera, Perú.

MOSELEY, M. E., 1992 - The Incas and their Ancestors, 272p.; London: Thames and Hudson Ltd.

OLSEN, K. M. \& SCHAAL, B. A., 1999 - Evidence on the origin of cassava: Phylogeography of Manihot esculenta. The National Academy of Sciences, 96: 5586-5591.

OLSEN, K. M. \& SCHAAL, B. A., 2001 - Microsatellite variation in cassava (Manihot esculenta, Euphorbiaceae) and its wild relatives: further evidence for a southern Amazonian origin of domestication. American Journal of Botany, 88: 131-142. 
PRÜMERS, H., 1989 - Tejidos del Horizonte Medio del Valle de Huarmey. In: The Nature of Huari. A reappraisal of the Middle Horizon Period in Peru (Michael R. Czwarno, Frank Meddens \& Alexandra Morgan, ed.): 188-213; Oxford: BAR International Series, 525.

PRÜMERS, H., 2000 - "El Castillo" de Huarmey: Una plataforma funeraria del Horizonte Medio. Boletín de Arquéología PUCP, 4: 289-312.

ROOSEVELT, A. C., 1980 - Parmana, Prehistoric Maize and Manioc Subsistence along the Amazon and Orinoco, 320p.; New York: Academic Press.

SHIMADA, I., 1994 - Pampa Grande and the Mochica Culture, 323p.; Austin: University of Texas Press.

STRONG, W. D. \& EVANS, C., 1952 - Cultural Stratigraphy in the Viru Valley, Northern Peru, 373p.; New York: Columbia University Studies in Archaeology and Ethnology 4.

UBBELOHDE-DOERING, H., 1983 - Vorspanische Gräber von Pacatnamú, Nordperu, 136p.; Munchen: Materialien zur Allgemeinen und Vergleichenden Archäologie, Band 26, Verlag C. H. Beck.

UCEDA, S., 1997 - El poder y la muerte en la sociedad Moche. In: Investigaciones en la Huaca de la Luna 1995 (Santiago Uceda, Elias Mujica \& Ricardo Morales, ed.): 177-188; Trujillo: Facultad de Ciencas Sociales, Universidad Nacional de La Libertad, Perú.

UGENT, D., POZORSKI, S. \& POZORSKI, T., 1986 - Archaeological Manio from Coastal Peru. Economic Botany, 40: 78-102.

WILSON, D. L., 1988 - Prehispanic Settlement Patterns In the Lower Santa Valley, Peru: A Regional Perspective on the Origins and Development of Complex North Coast Society, 590p.; Washington D.C.: Smithsonian Institution Press.

WILSON, D. L., 1999 - Indigenous South Americans of the Past and Present, An Ecological Perspective, 480p; Boulder: Westview Press, Colorado. 